\title{
Terapi Nonsteroid Anti Inflammatory Drug pada Bayi Prematur dengan Duktus Arteriosus Persisten
}

\author{
Sri Endah Rahayuningsih, Nono Sumarna, Armijn Firman, Yunita Sinaga,
}

\begin{abstract}
Duktus arteriosus persisten (DAP) adalah penyakit jantung bawaan yang terjadi pada 9$12 \%$ dari seluruh pasien penyakit jantung bawaan. Insidens DAP lebih tinggi pada bayi prematur, keadaan ini berhubungan dengan maturitas bayi. Penutupan duktus arteriosus persisten pada bayi prematur tidak selalu memerlukan terapi bedah, tetapi dapat dengan pemberian indometasin dan ibuprofen. Penelitian penelitian yang telah dilakukan menunjukkan bahwa ibuprofen mempunyai efek samping obat lebih sedikit dibandingkan dengan indometasin, sehingga ibuprofen dapat digunakan sebagai terapi DAP pada bayi prematur.
\end{abstract}

Kata kunci: duktus arteriosus persisten, prematur, ibuprofen

D uktus arteriosus persisten adalah suatu keadaan duktus arteriosus yang tetap terbuka lebih dari 15 jam setelah bayi lahir. Secara umum, angka kejadian DAP 1 per 2500-5000 kelahiran hidup pada bayi cukup bulan, 8 per 1000 kelahiran hidup pada bayi prematur dan merupakan 9-12\% dari seluruh penyakit jantung bawaan. ${ }^{1,2,3,4}$ Duktus arteriosus persisten sering dijumpai pada bayi prematur, insidensnya bertambah dengan berkurangnya masa gestasi. Pada bayi berat badan kurang dari 1500 gram dan mengalami distress pernafasan kira-kira 40\% mengalami duktus yang tetap terbuka. Pada bayi dengan berat badan kurang dari 1000 gram insidensinya mencapai 80\%. Insidensi DAP tampaknya berhubungan terbalik dengan berat badan lahir dan umur kehamilan.

Duktus arteriosus persisten dapat menyebabkan terjadinya perdarahan intraventrikular, necrotizing enterocolitis, bronchopulmonary dysplasia, bahkan dapat

\footnotetext{
Alamat Korespondensi:

Dr. Sri Endah Rahayuningsih, Sp.A

Bagian/SMF Ilmu Kesehatan Anak FKUP/RSUP dr. Hasan Sadikin Jl.

Pasteur No. 38

Telp./Fax. 2034426-203595 Bandung 40161
}

menyebabkan kematian. Penutupan DAP diharapkan dapat menurunkan angka kesakitan dan angka kematian. Penelitian-penelitian terdahulu menyatakan bahwa operasi penutupan DAP menurunkan angka kematian bayi karena dapat mengurangi lama penggunaan ventilator, memperbaiki hemodinamika, dan memperbaiki compliance paru. Namun operasi membutuhkan biaya yang cukup banyak dan tidak semua rumah sakit dapat mengerjakannya. ${ }^{5,6}$

Indometasin yang merupakan salah satu nonsteroid anti inflammatory drug (NSAID) dapat digunakan untuk terapi penutupan DAP pada bayi prematur. Namun, penelitian-penelitian sebelumnya menunjukkan indometasin dapat menimbulkan efek samping seperti gangguan fungsi ginjal, perdarahan gastrointestinal, dan gangguan aliran darah otak. Sehingga diperlukan NSAID lain yang dapat digunakan untuk penutupan DAP tetapi dengan efek samping yang rendah. Ibuprofen dapat digunakan sebagai terapi penutupan DAP dengan efek samping yang minimal. ${ }^{5,6}$ Penelitianpenelitian yang telah dilakukan menunjukkan bahwa ibuprofen ternyata tidak mempengaruhi aliran darah ke otak, tidak menyebabkan gangguan pada ginjal, dan gastrointestinal. Penelitian pada hewan percobaan menunjukkan bahwa ibuprofen memperbaiki autoregulasi aliran darah ke otak, walaupun pada manusia hal ini belum diteliti. 


\section{Penutupan Duktus Arteriosus}

Duktus arteriosus menutup secara fungsional pada 1015 jam setelah lahir, jadi adanya hubungan (pirau) berlangsung sangat singkat. Penutupan permanen terjadi pada usia 2-3 minggu. ${ }^{1,2,5,7}$ Bila terjadi hipoksia (akibat penyakit paru, asfiksia dan lain-lain) maka tekanan arteri pulmonalis meningkat dan terjadi aliran pirau berbalik dari arteria pulmonalis ke aorta melalui duktus arteriosus, dalam keadaan ini tidak terjadi penutupan duktus.

Faktor-faktor yang diduga berperan dalam penutupan duktus. ${ }^{1,5}$

- Peningkatan tekanan oksigen arteri $\left(\mathrm{PaO}_{2}\right)$ menye babkan konstriksi duktus, sebaliknya hipoksia akan menyebabkan duktus melebar. Karena itulah duktus arteriosus persisten lebih banyak ditemukan pada keadaan dengan $\mathrm{PaO}_{2}$ yang rendah, termasuk bayi dengan sindrom gangguan pernafasan, prematu ritas, dan bayi yang lahir di dataran tinggi.

- Peningkatan kadar katekolamin (norepinefrin, epi nefrin) berhubungan dengan konstriksi duktus.

- Penurunan kadar prostaglandin berhubungan dengan penutupan duktus, sebaliknya pemberian prostaglandin eksogen menghalangi penutupan duktus. ${ }^{2,5,6}$

\section{Pendahuluan}

Duktus arteriosus persisten adalah suatu keadaan duktus arteriosus yang tetap terbuka lebih dari 15 jam setelah bayi lahir. Secara umum, angka kejadian DAP 1 per 2500-5000 kelahiran hidup pada bayi cukup bulan, 8 per 1000 kelahiran hidup pada bayi prematur dan merupakan 9-12\% dari seluruh penyakit jantung bawaan. ${ }^{1,2,3,4}$ Duktus arteriosus persisten sering dijumpai pada bayi prematur, insidensnya bertambah dengan berkurangnya masa gestasi. Pada bayi berat badan kurang dari 1500 gram dan mengalami distress pernafasan kira-kira 40\% mengalami duktus yang tetap terbuka. Pada bayi dengan berat badan kurang dari 1000 gram insidensinya mencapai $80 \%$. Insidensi DAP tampaknya berhubungan terbalik dengan berat badan lahir dan umur kehamilan.

Duktus arteriosus persisten dapat menyebabkan terjadinya perdarahan intraventrikular, necrotizing enterocolitis, bronchopulmonary dysplasia, bahkan dapat menyebabkan kematian. Penutupan DAP diharapkan dapat menurunkan angka kesakitan dan angka kematian. Penelitian-penelitian terdahulu menyatakan bahwa operasi penutupan DAP menurunkan angka kematian bayi karena dapat mengurangi lama penggunaan ventilator, memperbaiki hemodinamika, dan memperbaiki compliance paru. Namun operasi membutuhkan biaya yang cukup banyak dan tidak semua rumah sakit dapat mengerjakannya.,

Indometasin yang merupakan salah satu nonsteroid anti inflammatory drug (NSAID) dapat digunakan untuk terapi penutupan DAP pada bayi prematur. Namun, penelitian-penelitian sebelumnya menunjukkan indometasin dapat menimbulkan efek samping seperti gangguan fungsi ginjal, perdarahan gastrointestinal, dan gangguan aliran darah otak. Sehingga diperlukan NSAID lain yang dapat digunakan untuk penutupan DAP tetapi dengan efek samping yang rendah. Ibuprofen dapat digunakan sebagai terapi penutupan DAP dengan efek samping yang minimal. ${ }^{5,6}$ Penelitian-penelitian yang telah dilakukan menunjukkan bahwa ibuprofen ternyata tidak mempengaruhi aliran darah ke otak, tidak menyebabkan gangguan pada ginjal, dan gastrointestinal. Penelitian pada hewan percobaan menunjukkan bahwa ibuprofen memperbaiki autoregulasi aliran darah ke otak, walaupun pada manusia hal ini belum diteliti.

\section{Penutupan Duktus Arteriosus}

Duktus arteriosus menutup secara fungsional pada 10-15 jam setelah lahir, jadi adanya hubungan (pirau) berlangsung sangat singkat. Penutupan permanen terjadi pada usia 2-3 minggu. ${ }^{1,2,5,7}$ Bila terjadi hipoksia (akibat penyakit paru, asfiksia dan lain-lain) maka tekanan arteri pulmonalis meningkat dan terjadi aliran pirau berbalik dari arteria pulmonalis ke aorta melalui duktus arteriosus, dalam keadaan ini tidak terjadi penutupan duktus.

Faktor-faktor yang diduga berperan dalam penutupan duktus. ${ }^{1,5}$

- Peningkatan tekanan oksigen arteri $\left(\mathrm{PaO}_{2}\right)$ me nyebabkan konstriksi duktus, sebaliknya hipoksia akan menyebabkan duktus melebar. Karena itulah duktus arteriosus persisten lebih banyak ditemukan pada keadaan dengan $\mathrm{PaO}_{2}$ yang rendah, termasuk bayi dengan sindrom gangguan pernafasan, prematuritas, dan bayi yang lahir di dataran tinggi.

- Peningkatan kadar katekolamin (norepinefrin, 
epinefrin) berhubungan dengan konstriksi duktus.

- Penurunan kadar prostaglandin berhubungan dengan penutupan duktus, sebaliknya pemberian prosta glandin eksogen menghalangi penutupan duktus. ${ }^{2,5,6}$

\section{Pengelolaan DAP}

Pada prinsipnya, penanganan pasien DAP adalah menutup duktus yang ada, tetapi penutupan duktus ini hanya dilakukan bila tidak disertai kelainan jantung lainnya yang justru membutuhkan duktus ini sebagai sumber suplai darah. Karena struktur duktus arteriosus berbeda antara bayi cukup bulan dan bayi prematur maka terdapat perbedaan dalam penanganannya. Pada bayi cukup bulan dengan duktus arteriosus yang masih tetap terbuka pada akhir minggu pertama, kemungkinan besar duktus tidak akan dapat menutup dengan pemberian inhibitor prostaglandin. Sebaliknya pada bayi prematur, walaupun pada akhir minggu pertama duktus masih terbuka kemungkinan duktus dapat menutup dengan pemberian inhibitor prostaglandin seperti indometasin dan ibuprofen ${ }^{2,5,6,8}$

Berdasarkan percobaan pada binatang penggunaan inhibitor sintesis prostaglandin akan menghambat siklooksigenase yang akan mengubah asam arahkidonat menjadi prostaglandin sehingga terjadi penurunan prostaglandin yang dapat menyebabkan penutupan duktus arteriosus. ${ }^{2,9}$

Penelitian tentang pengaruh inhibitor prostaglandin terhadap penutupan DAP telah dilakukan sejak tahun 70 -an. Saat itu obat yang sering digunakan adalah indometasin. Ternyata setelah penggunaan indometasin terdapat penurunan angka morbiditas dan mortalitas pada bayi-bayi prematur dengan DAP.,10

Pada bayi prematur DAP dapat menyebabkan gagal jantung, gangguan pada paru, gangguan fungsi ginjal dan saluran cerna, risiko terjadinya perdarahan intraventrikular serta bronkopulmonal displasia (BPD). Gejala gejala tersebut terjadi pada .hari kedua sampai ketiga pasca natal. Terapi konservatif gagal jantung pada bayi prematur yang meliputi restriksi cairan, pemberian diuretik serta pemberian digitalis yang sampai saat ini masih kontroversi pada bayi berat badan lebih rendah khususnya kurang dari 1250 gram. ${ }^{11}$ Pemberian diuretik dan restriksi cairan pada bayi prematur memerlukan observasi yang ketat, karena dapat menyebabkan ketidakseimbangan elektrolit, dehidrasi serta kekurangan kalori. ${ }^{11,12}$
Sehingga dianjurkan untuk memberikan indometasin pada bayi prematur dengan berat badan lahir kurang dari 1500, sebelum gejala gejala tersebut timbul dan dikenal sebagai terapi profilaksis. ${ }^{13}$ Pemberian indometasin intravena dengan dosis $0,2 \mathrm{mg} / \mathrm{kg} \mathrm{BB}$ sebagai dosis awal, yang kemudian dilanjutkan dengan dosis kedua dan ketiga sebanyak $0,1 \mathrm{mg} / \mathrm{kg}$ BB yang diberikan dengan interval 12-24 jam menunjukkan hasil yang bermakna (kelompok yang mendapat indometasin mengalami penutupan sebanyak $79 \%$ dibandingkan plasebo sebanyak 35\%). ${ }^{11,14}$ Beberapa peneliti mengemukakan bahwa dengan pemberian indometasin pada 12 jam pertama kehidupan dapat menurunkan kejadian DAP, sedangkan peneliti lain memberikannya pada usia 2-8 hari. ${ }^{11,14}$ Walaupun efek dari indometasin terhadap penutupan duktus arteriosus cukup bagus, ternyata tidak semua bayi DAP yang mendapat terapi indometasin menutup secara permanen. Sekitar 30\% duktus yang telah menutup dengan pemberian indometasin dapat terbuka kembali. Beberapa peneliti menemukan bahwa terbukanya duktus ini adalah kecil dan akan menutup kembali, tetapi peneliti lain menemukan adanya tanda-tanda DAP kembali. Terbukanya kembali duktus arteriosus berhubungan dengan berat badan lahir bayi. Bayi yang tidak memberikan respons terhadap terapi ulangan indometasin, umumnya bayi sudah mendekati cukup bulan. Untuk mencegah terbukanya kembali duktus arteriosus ini beberapa peneliti menganjurkan pemberian indometasin dosis pemeliharaan selama 57 hari, tetapi penelitian lainnya menemukan bahwa tidak ada perbedaan kejadian ini walaupun tidak diberikan terapi pemeliharaan sehingga terapi pilihan selanjutnya adalah bedah. ${ }^{11,12,14}$

Efek samping pemberian indometasin berupa penurunan fungsi ginjal sementara, enterokolitis nekrotikans, perdarahan saluran cerna, gangguan aliran darah otak. Kontraindikasi pemberian indometasin bersifat relatif, yaitu fungsi ginjal yang buruk, gangguan perdarahan serta trombosit yang rendah, enterokolitis nekrotikans, dan sepsis. Sehingga sebelum pemberian indometasin perlu dilakukan evaluasi klinis maupun laboratorium untuk menghindari efek samping tersebut. ${ }^{11,13}$

Akibat banyaknya efek samping yang disebabkan indometasin, beberapa peneliti mencoba mencari obatobat penghambat enzim siklooksigenase yang lain dengan efek samping yang lebih sedikit. Pada tahun 80 -an mulai diberikan ibuprofen pada binatang 
percobaan. Ternyata hasil yang didapatkan hampir sama dengan indometasin tetapi efek samping yang ditimbulkannya lebih sedikit. Dan tahun 90-an penelitian ini mulai dilakukan pada manusia. ${ }^{13,15,16,17}$ Pemberian ibuprofen yang dianjurkan melalui intravena selama 15 menit atau melalui pipa nasogastrik dengan dosis $10 \mathrm{mg} / \mathrm{kg} \mathrm{BB}$, dilanjutkan dengan $5 \mathrm{mg} / \mathrm{kg}$ BB setelah 24 dan 48 jam dari pemberian pertama. ${ }^{12,15,16}$

Dari penelitian yang dilakukan oleh beberapa peneliti ditemukan bahwa penutupan duktus setelah pemberian indometasin dan ibuprofen hampir sama masing-masing $80 \%$ dan $70 \%$,

- Pemberian ibuprofen menunjukkan efek samping yang lebih rendah dibandingkan indometasin, sehingga ibuprofen dapat digunakan sebagai terapi DAP pada bayi prematur. ${ }^{12,15,16}$

- Ibuprofen tidak mempengaruhi aliran darah otak, tidak menyebabkan gangguan pada ginjal, dan gastrointestinal.

\section{Daftar Pustaka}

1. Sadler TW. Perubahan peredaran darah pada saat kelahiran. Dalam: Langman embriologi kedokteran, alih bahasa Susanto I. Edisi ke-5. Jakarta: EGC; 1988:209-13.

2. Clynmann, RI. Developmental physiology of the ductus arteriosus. Dalam: Long WA, penyunting. Fetal and neonatal cardiology. Philadelphia:WB Saunders, 1990. h. 64-75.

3. Huhta JC. Patent ductus arteriosus in preterm neonate. Dalam: penyunting. Fetal and neonatal cardiology. Philadelphia:WB Saunders, 1990. h. 682-759.

4. Breinstein D. Epidemiology of congenital heart disease. Dalam: Behrman RE, Kliegman RM, Jenson HB, penyunting. Nelson textbook of pediatrics, edisi ke-16. Philadelphia: WB Saunders, 2000. h. 1362-3.

5. Breinstein D. Fetal circulation. Dalam: Behrman RE, Kliegman RM, Jenson HB, penyunting. Nelson textbook of pediatrics, edisi ke-16. Philadelphia: WB Saunders, 2000. h. 1365-4.

6. Clynmann, RI. Medical treatment of patent ductus arteriosus in premature infants. Dalam: Long WA, penyunting. Fetal and neonatal cardiology. Philadelphia: WB Saunders, 1990. h. 682-759.

7. Brook MM, Heyman MA. Patent ductus arteriosus. Dalam: Emmanoulidies GC, Riemenschneider TA, Allen
HD, Gutgesell HP, penyunting. Moss and Adams heart disease in infants, children, adolescents including the fetus and young adult, edisi ke-9. Baltimore: William and Wilkins, 1995. h. 746-62.

8. Chang, AC, Wells W. Patent ductus arteriosus. Dalam: Chang AC, Hanley FL, Wernovsky G, Wessel DL, penyunting. Pediatric cardial intensive care. Baltimore: William and Wilkins, 1998. h. 203-7.

9. Bada HS, Green RS, Pourcyrous M. Indomethacin reduces the risk of severe intraventricular hemorrhage. J. Pediatr 1989;115:631-37

10. Couser RJ, Ferrara TB, Wright GB, et al. Indomethacin (INDO) prophytheraphy in the first twenty-four hours of life for the prevention of patent ductus arteriosus in preterm infants treated prophylactically with surfactant in the delivery room. J. Pediatr 1996; 128:631-37.

11. Clynmann, RI. Recommendation for the post natal use of indomethacin: an analysis of four separate treatment strategies. Dalam: Long WA, penyunting. Fetal and neonatal cardiology. Philadelphia: WB Saunders, 1990. h. 601-17.

12. Firemann, JR, Soifer SJ. The fetal and neonatal circulation. Dalam: Long WA, penyunting. Fetal and neonatal cardiology. Pediatric cardial intensive care. Baltimore: William and Wilkins, 1998. h. 17-23.

13. Overmeine BV, Follens I, Hartmann S, Creten WL, Acker KJ. Treatment of patent ductus arteriosus with ibuprofen. Arch Dis Chil, 1997;76:F179-84.

14. Shejerdemian LS. Redington A. Cardiovascular pharmacology. Dalam: Long WA, penyunting. Fetal and neonatal cardiology. Pediatric cardial intensive care. Baltimore: William and Wilkins, 1998. h. 59-44.

15. Varvarigo N, Bardin CL. Beharry K, Chemtob S, Papergeorgio (A) Aranda JV. Early ibuprofen administration to prevent patent ductus arteriosus in premature infants. JAMA. 1996;275-539-44.

16. Mosca F, Bray M, Lattanzio M. Fumagalli, Tosetto C. Comparative evaluation of the effect of indomethacin and ibuprofen on cerebral perfusion and oxygenation in preterm infant with patent ductus arteriosus. J. Pediatr 1997; 131:549-54.

17. Bernstein D. Patent ductus arteriosus. Dalam: Behrman RE, Kliegman RM, Jenson HB, penyunting. Nelson textbook of pediatrics, edisi ke-16. Philadelphia: WB Saunders, 2000. h. 1372-3.

18. Ho Sy, Angenili A, Moscoso G. Developmental cardial anatomy. Patent ductus arteriosus in premature infants. Dalam: Long WA, penyunting. Fetal and neonatal cardiology. Philadelphia:WB Saunders, 1990. h. 682-759. 